\title{
Impulse control and related disorders in Parkinson's disease
}

\author{
Transtorno de controle de impulso e condições relacionadas na doença de Parkinson \\ Antonio Pedro Vargas? ${ }^{1}$ Francisco Eduardo Costa Cardoso²
}

\begin{abstract}
Neuropsychiatric disorders are common among patients with Parkinson's disease and may appear in any stage of the disease. However, these disorders often go undiagnosed and receive insufficient treatment. Observations in recent years have revealed that dopamine replacement therapy may lead to the development or worsening of conditions, such as gambling disorder, compulsive sexual behavior, compulsive buying and binge eating, in addition to punding and dopamine dysregulation syndrome. The pathophysiology of these disorders seems to be related to abnormal dopaminergic stimulation of the basal regions of the basal ganglia, especially via nigro-mesolimbic pathways. The aim of the present study was to perform a literature review on impulsivity, impulse control disorders and related conditions among patients with Parkinson's disease, with emphasis on their epidemiology, clinical characteristics and treatment.
\end{abstract}

Keywords: Parkinson's disease; disruptive, impulse control, and conduct disorders; levodopa; dopamine agonists; impulsive behavior; bulimia.

\section{RESUMO}

Alterações neuropsiquiátricas são comuns na doença de Parkinson e estão presentes em todas as fases da enfermidade. No entanto, frequentemente não são reconhecidas e recebem tratamento insuficiente. Ao longo dos últimos anos, observou-se que a terapia de reposição dopaminérgica pode levar ao desenvolvimento ou piora de condições como transtorno do jogo, compulsão por sexo, compras, e comida, além da síndrome de desregulação dopaminérgica e punding. Sua fisiopatologia parece estar relacionada à estimulação dopaminérgica anormal das regiões basais dos núcleos da base, sobretudo pelas vias nigro-mesolímbicas. O presente artigo tem como objetivo fazer uma revisão da literatura a respeito de impulsividade, transtornos do controle de impulso e condições relacionadas na doença de Parkinson, com foco na epidemiologia, características clínicas e tratamento.

Palavras-chave: doença de Parkinson; transtornos disruptivos, de controle do impulso e da conduta; levodopa; agonistas de dopamina; comportamento impulsivo; bulimia.

\section{IMPULSE CONTROL DISORDERS}

Impulsivity can be defined as a predisposition to immediate and unplanned reactions to internal or external stimuli before thoroughly processing the information and with no regard for the long-term consequences of a behavior ${ }^{1}$. The decision-making process is influenced by the individual's ability to store and manipulate information, plan and assess different options and translate thought into action. Therefore, impulsivity plays an important role in normal behavior (job and school performance, for instance) and in several classes of psychiatric and neurological disorders. Nevertheless, consensus has not been reached on what distinguishes socially acceptable and dysfunctional impulsive behaviors, which vary as a function of time and between different cultures ${ }^{1}$.

Impulsivity is the main symptom of impulse control disorders (ICDs), which are characterized by engagement in repetitive and compulsive activities despite their adverse consequences ${ }^{2}$. Patients are unable to resist an impulse, even though it may potentially be risky. They report irresistible, intrusive and senseless impulses. This combination of symptoms leads to stress and interferes with the individuals' social and occupational functioning. However, performance of the problem behavior is pleasurable. They may feel regret or guilt, but these symptoms are seldom reported because admitting this may cause embarrassment or the behavior may be considered normal.

${ }^{1}$ Rede SARAH de Hospitais de Reabilitação, Departamento de Neurologia, Belo Horizonte MG, Brasil;

${ }^{2}$ Universidade Federal de Minas Gerais, Unidade de Distúrbios do Movimento, Departamento de Clínica Médica, Serviço de Neurologia, Belo Horizonte MG, Brasil.

Correspondence: Francisco Cardoso;Av Pasteur, 89 / 1107;30150-290 Belo Horizonte MG, Brasil; E-mail: cardosofe@terra.com.br

Conflict of interest: There is no conflict of interest to declare.

Received 10 January 2018; Received in final form 01 March 2018; Accepted 17 March 2018. 
Impulse control disorders are similar to obsessive-compulsive disorders because patients experience difficulties resisting the desire to involve themselves in specific behaviors that interfere with their typical activities ${ }^{2}$. Impulse control disorders are also similar to the disorders associated with substance use and dependence because the affected individuals develop tolerance and abstinence symptoms. One characteristic that distinguishes ICDs from obsessive-compulsive disorders and brings them closer to the disorders associated with substance abuse is the ego-syntonic nature of the behaviors ${ }^{2}$. The motivational and emotional processes that lead individuals to engage in repetitive activities may change over time. Therefore, the eagerness to perform an impulsive behavior becomes more ego-dystonic, i.e., less related to the search for pleasure and more oriented to the need to reduce a state of anxiety and stress.

The mesolimbic dopaminergic pathway has a central role in the development of ICDs because the feelings of reward derived from dopamine release within this system may be responsible for the symptoms associated with chemical and behavioral dependence ${ }^{3}$. Dopamine regulates the salience of external stimuli. Pleasurable stimuli induce a tonic dopaminergic response in the nucleus accumbens. However, repeated stimuli induce the habituation phenomenon. In the brainstem, dopaminergic autoreceptors located in the substantia nigra provide feedback to regulate the synaptic dopamine concentration. The orbitofrontal and anterior cingulate cortices are responsible for weighing the relevance of reward and linking it to an adequate response. The prefrontal cortex inhibits goal-directed (reward) responses, thus having a balancing effect on the system. When all these elements work correctly, individuals are able to successfully adjust their behavior in constantly changing environments ${ }^{3}$.

Among individuals with ICD, the midbrain tonic dopaminergic signals attribute more relevance to addictive stimuli. Following repetitive exposure, the stimulus-pleasure association becomes a stimulus-action directed to an addictive input signal. The descending cortical control seems to be impaired with less activation of the prefrontal cortex. Persistent D2 receptor activation may reduce the influence of the prefrontal cortex, thus reducing flexibility and not allowing specific goal-oriented behavioral changes. Continuous directional firing of hippocampal neurons makes the individual persevere with impulsive tasks ${ }^{3}$.

The DSM-IV-TR formally recognizes the following as ICDs: intermittent explosive disorder, kleptomania, pyromania, trichotillomania, gambling disorder and other unspecified ICDs ${ }^{2,4}$. Compulsive sexual behavior, compulsive buying and problematic Internet use are examples of unspecified ICDs. This classification was revised in the DSM-5. As a function of clinical and biological similarities with substance use disorders, gambling disorder was reclassified as a behavioral addiction $^{5}$. Compulsive sexual behavior, compulsive buying and other ICDs can also be considered addictive disorders ${ }^{2,4}$.

According to estimates, $10 \%$ of the overall population meets the criteria for at least one episode of ICD in their life ${ }^{4}$. Symptoms tend to appear at the end of adolescence or beginning of adult life. A few epidemiological studies have been performed on ICDs among older adults. One such study assessed patients over 60 years old and found a $22.4 \%$ prevalence of at least one ICD episode in life ${ }^{6}$.

Approximately one-third of patients with psychiatric disorders exhibit one or more ICDs ${ }^{4}$. As many as $96 \%$ of individuals with a lifetime gambling disorder also meet the criteria for at least one other lifetime psychiatric disorder, especially mood disorder (20\% to $55.6 \%$ ), substance abuse (35\% to $76.3 \%$ ), anxiety $(41.3 \%$ to $60.3 \%)$ and personality disorders $(68.8 \%)^{2,4}$. An ICD was also found among patients with pituitary adenoma, restless legs syndrome ${ }^{8}$ and Parkinson's disease (PD), ${ }^{9,10}$ especially those under treatment with dopaminergic agents.

\section{Gambling disorder}

Patients experience intrusive and repetitive thoughts about gambling ${ }^{5}$. They spend most of their time on activities related to gambling and neglect their daily responsibilities. They lose control of their finances and become manipulative and deceitful. They avoid friends and social events and lie and steal from relatives and acquaintances. Personal relationships deteriorate. They lose their jobs for lack of credibility and absenteeism. They develop tolerance and exhibit abstinence symptoms and relapses on attempts to quit the habit ${ }^{2,5}$. They feel guilt and regret but become irritated and hostile when deprived of opportunities for gambling.

\section{Compulsive buying}

Patients have an exaggerated interest in buying, experiencing unnecessary debt ${ }^{2}$. They purchase goods they do not need and spend a large part of their time shopping.

\section{Binge eating}

The most frequent clinical presentation of binge eating is an exaggerated increase of food intake within short intervals of time with cravings for sweets, fried savory snacks and carbohydrate-rich foods ${ }^{2}$. Compensatory behaviors, such as selfinduced vomiting, do not occur in this disorder. Involuntary and undesired weight gain is frequent.

\section{Sexual compulsion (hypersexuality)}

Compulsive sexual behavior involves preoccupation with sexual gratification beyond accepted personal and social limits $^{2}$. Patients exhibit intense and recurrent sexual behaviors, which cause distress and consume enough time to interfere with their social and occupational activities. Patients describe themselves as out of control.

\section{IMPULSE CONTROL DISORDERS AMONG PATIENTS WITH PD}

\section{Prevalence}

One relevant issue is whether ICDs are more common among patients with PD compared with the overall 
population. In one cross-sectional, multicenter study carried out on 87 patients with early-onset PD and 87 matched healthy controls, ICDs were more common among patients with PD ( $58.3 \%$ vs. $32.9 \%, p=0.001)^{11}$. However, most of the patients who displayed an ICD (91.8\%) were medicated with a dopamine agonist (DA). Many authors argue that PD alone does not confer an increased risk for development of ICD symptoms ${ }^{12,13}$. According to some reports, patients with PD who had not yet started treatment with dopaminergic drugs exhibited a similar frequency of ICDs when compared with individuals without neurological diseases $(18.5 \% \text { vs } 20.3 \%, p=0.19)^{12}$. One study found that the frequency of ICDs among patients with PD before the onset of dopamine replacement therapy did not increase after one year of use of medication ${ }^{13}$. These results suggest that subclinical behavioral abnormalities are as common among patients with PD as in the overall population.

Impulse control disorders often go undiagnosed among patients with PD. Most patients do not spontaneously provide information on impulsive behaviors due to shame or unawareness that such symptoms may be related to PD and its treatment ${ }^{9}$. DOMINION, the largest cross-sectional multicenter study on the association of ICDs and PD conducted in North America, found that $13.6 \%$ of patients exhibited some ICD (5.7\% buying compulsion, $5 \%$ gambling disorder, $3.5 \%$ impulsive sexual behavior and $4.3 \%$ binge eating $)^{14}$. ICARUS, an Italian prospective multicenter study that assessed 1,069 PD patients treated with dopaminergic medication at three time-points over two years, found stable narrow-scope ICD prevalence rates: $28.6 \%$ at baseline, $29.3 \%$ at the one-year assessment and $26.5 \%$ after two years ${ }^{15}$. The most prevalent type was binge eating $(9.9 \% ; 11.4 \% ; 10.6 \%)$ followed by compulsive sexual behavior (9.7\%; 14.6\%; 9\%), gambling disorder $(5.3 \%$; $5.4 \%$; $4.9 \%)$ and compulsive buying $(6.5 \%$; $6.1 \%$; $10.1 \%)$. A study conducted in Korea assessed 1,167 patients and found a narrow-scope prevalence of $7.6 \%$, corresponding to binge eating $3.4 \%$; hypersexuality $2.8 \%$; compulsive buying $2.5 \%$; and gambling disorder $1.3 \%{ }^{16}$.

The many similarities notwithstanding, the prevalence of ICD and its subtypes in PD exhibit considerable variability among studies, as shown in Table 1. The methods (multicenter versus single-center studies, cross-sectional versus prospective design), information sources (patients versus relatives), screening instruments, inclusion or non-inclusion of subclinical cases, population sample (community versus specialized services, patients with or without dementia), availability of dopaminergic medication, demographic and cultural conditions varied considerably among the studies; hence, the results were not systematically concordant ${ }^{17}$. Table 2 shows an overview of studies on ICDs in PD patients.

Two studies conducted in Spain reported increased prevalence rates compared with the DOMINION study but similar to the ones found in the ICARUS study $\left(23.5 \%{ }^{18}\right.$ and $\left.39 \%{ }^{19}\right)$. In the first study, hypersexuality and binge eating were the most frequent ICDs ${ }^{18}$. The second study assessed only patients who had used dopaminergic agonists for at least six months ${ }^{19}$. A French study reported $25 \%$ prevalence of at least one ICD: $14 \%$ for binge eating, $10 \%$ for hypersexuality, $6 \%$ for compulsive buying and $3 \%$ for gambling disorder ${ }^{20}$. Another study, also performed in France, found $12 \%$ and $3 \%$ prevalence rates of gambling disorder and hypersexuality, respectively, among patients ${ }^{21}$. A study conducted in Italy reported a prevalence rate of $8.1 \%$. This rate is less than those reported in the ICARUS and DOMINION studies, but similar to that obtained in the South Korean study ${ }^{22}$. This difference may be attributed to the inclusion of patients with dementia (26\%), as the prevalence of ICDs in this subgroup was reduced compared with patients without severe cognitive dysfunction (3.8\% versus 9.6\%). In one study, performed in Finland, the prevalence of ICDs was increased, compared with other studies, at $34.8 \%$ for at least one disorder ${ }^{23}$. Compulsive sexual behavior was found in $22.8 \%$, binge eating in $11.8 \%$, compulsive buying in $10.1 \%$ and gambling disorder in $8.8 \%$ of patients. In a Danish cohort, ICDs occurred among $35.9 \%$ of patients at some time in the course of PD, although $14.9 \%$ of them exhibited symptoms at the time of the study, a frequency similar to the one reported in the DOMINION study ${ }^{24}$. Hypersexuality was reported by $9 \%$, binge eating by $8.6 \%$, compulsive buying by $7.3 \%$ and gambling disorder by $7.1 \%$ of the sample.

Very low prevalence rates of $3.53 \%$ for ICDs were reported in a Chinese study (hypersexuality 1.92\%; gambling disorder $0.32 \%$; binge eating $0.32 \%$; problematic Internet use $0.32 \%)^{25}$. These results are not consistent with findings for Shanghai (global prevalence of ICDs of 31\%; gambling disorder and binge eating being the most prevalent) ${ }^{26}$ and Hong Kong (global prevalence 7\%; gambling disorder and hypersexuality being the most frequent types ${ }^{27}$. In Taiwan, the reported prevalence of ICDs among patients with PD was lower, at 4.49\% (hypersexuality 2.99\%; gambling disorder $1.49 \%$; binge eating $0.37 \%)^{28}$. A less widespread use of levodopa and DAs, methodological, cultural and demographic differences-even within the same country or ethnic group-may account for such discrepancies ${ }^{25,26,27,28}$.

Four epidemiological studies were conducted in Latin America. The Brazilian study, which was performed in Salvador, Bahia, investigated 152 patients with PD and reported an $18.4 \%$ prevalence of ICDs ${ }^{29}$. Hypersexuality was the most common type (11.8\%) followed by compulsive buying (10.5\%). An increased prevalence rate was reported in a study conducted at three South American centers: Argentina - 32.5\%, Ecuador $-21.7 \%$, and Colombia $-25.7 \%$ (binge eating $-45 \%$ of patients with ICD $)^{30}$. Two studies performed in Mexico reported lower prevalence rates $\left(12.6 \%^{31}\right.$ and $\left.10.6 \%{ }^{32}\right)$, with the most common type of ICD being binge eating $(8.6 \%)^{32}$.

Economic and sociocultural differences may account for how ICDs manifest in different populations 9 . A gambling disorder is more common in the United States and northern European countries ${ }^{14,23,24}$, and less frequent in Canada ${ }^{29}$, Asia and South America ${ }^{25,27,29,30}$. Availability of casinos, incentives and facilities for gambling seem to account for these 
differences. Greater interest in gastronomy and the meaning attributed to meals as factors of social cohesion may explain the increased prevalence of binge eating in Latin European and American countries ${ }^{15,20,30,31,32}$. Compulsive buying seems to occur more frequently in industrialized countries, where consumerism is more developed and credit is more easily available $^{26}$. Patients with low incomes, or residing in locations with scarce social security resources, may not have the economic conditions required to engage in gambling or shopping, thus they channel impulsivity to other types of behaviors ${ }^{32}$.

Table 1. Prevalence of different impulse control disorders and related conditions in Parkinson's disease patients.

\begin{tabular}{|c|c|c|c|c|c|c|c|c|c|c|}
\hline Study & Country & $\begin{array}{l}\text { Total PD } \\
\text { patients }\end{array}$ & ICD \% & GD \% & HS \% & $\mathrm{CB} \%$ & $\mathrm{BE} \%$ & $\begin{array}{l}\text { Multiple } \\
\text { ICD \% }\end{array}$ & $\begin{array}{c}\text { Punding } \\
\text { and related } \\
\text { behaviors \% }\end{array}$ & DDS \% \\
\hline Weintraub et al. (2010) ${ }^{14}$ & $\begin{array}{l}\text { United States } \\
\text { and Canada }\end{array}$ & 3090 & 13.6 & 5 & 3.5 & 5.7 & 4.3 & 3.9 & - & - \\
\hline Weintraub et al. (2013) & $\begin{array}{l}\text { United States } \\
\text { and Canada }\end{array}$ & 311 & 18.5 & 1.2 & 4.2 & 3 & 7,1 & & $\begin{array}{c}\text { Hobbyism } 5.4 \\
\text { Punding } 4.8 \\
\text { Walkabout } 0.6\end{array}$ & - \\
\hline Vela et al. (2016) & Spain & 87 & 58.3 & 10.7 & 23.8 & 15.5 & 20.2 & & $\begin{array}{l}\text { Hobbyism } 29.8 \\
\text { Punding } 17.9\end{array}$ & - \\
\hline Antonini et al. (2011) & Italy & 103 & 17.5 & 0.9 & 11 & 11 & - & - & - & - \\
\hline Antonini et al. (2017) & Italy & 1069 & $\begin{array}{l}28.6 \\
29.3 \\
26.5\end{array}$ & $\begin{array}{l}5.3 \\
5.4 \\
4.9\end{array}$ & $\begin{array}{c}9.7 \\
14.6 \\
9\end{array}$ & $\begin{array}{c}6.5 \\
6.1 \\
10.1\end{array}$ & $\begin{array}{l}9.9 \\
11.4 \\
10.6\end{array}$ & 15.4 & $\begin{array}{c}\text { Hobbyism } \\
12.8 \\
12.1 \\
10.9 \\
\text { Punding } \\
6.9 \\
7 \\
7.6 \\
\text { Walkabout } 2.3 \\
1.3 \\
1.8\end{array}$ & $\begin{array}{l}4.8 \\
3.5 \\
4.5\end{array}$ \\
\hline Lee et al. $(2010)^{16}$ & South Korea & 1167 & 10.1 & 1.3 & 2.8 & 2.5 & 3.4 & 2.91 & 4.2 & - \\
\hline Sáez-Francàs et al. (2015)18 & Spain & 115 & 23.48 & 2.6 & 12.2 & 3.5 & 10.1 & 5.22 & - & - \\
\hline Garcia-Ruiz et al. $(2014)^{19}$ & Spain & 233 & 39.1 & 3.86 & 12 & 6.87 & 2.58 & 15.88 & $\begin{array}{l}\text { Hobbyism } 19.33 \\
\text { Punding } 12.45 \\
\text { Walkabout } 1.29\end{array}$ & 3 \\
\hline Perez-Lloret et al. (2012) & France & 203 & 25 & 3 & 10 & 6 & 14 & 5 & - & - \\
\hline De Chazeron et al. (2011) ${ }^{21}$ & France & 115 & 2.61 & 0.87 & 1.7 & - & - & - & - & - \\
\hline Poletti et al. $(2013)^{22}$ & Italy & 805 & 8.1 & 3.2 & 3 & 1 & 2.4 & 1.61 & 0.2 & 0.2 \\
\hline Joutsa et al. (2012) ${ }^{23}$ & Finland & 575 & 34.8 & 8.8 & 22.8 & 10.1 & 11.8 & 12.5 & $\begin{array}{c}\text { Hobbyism } 22.6 \\
\text { Punding } 15.7 \\
\text { Walkabout } 6\end{array}$ & - \\
\hline Callesen et al. (2013) 24 & Denmark & 490 & $\begin{array}{c}35.9 * \star \\
(14.9) \star \star \star\end{array}$ & 7.1 & 9 & 7.3 & 8.6 & 23.3 & $\begin{array}{c}\text { Hobbyism } 16.7 \\
\text { Punding } 5.1 \\
\text { Walkabout } 5.1\end{array}$ & 6.9 \\
\hline Fan et al. (2009) ${ }^{25}$ & China & 312 & 3.53 & - & 1.92 & - & - & - & - & - \\
\hline Zhang et al. $(2017)^{26}$ & China & 142 & 31 & 7 & 2.8 & 4.9 & 5.6 & 11.27 & $\begin{array}{c}\text { Hobbyism } 6.3 \\
\text { Punding } 9.2 \\
\text { Walkabout } 1.4\end{array}$ & 11.3 \\
\hline Auyeung et al. (2011)27 & $\begin{array}{l}\text { China (Hong } \\
\text { Kong) }\end{array}$ & 213 & 7 & 6.1 & 3.76 & 0.47 & 0.47 & 3.7 & - & - \\
\hline Chiang et al. $(2011)^{28}$ & Taiwan & 268 & 5.6 & 1.49 & 2.99 & 0 & 0.37 & 0.37 & 0.37 & 1.12 \\
\hline Valença et al. (2013) & Brazil & 152 & 18.4 & 1.3 & 11.8 & 10.5 & 7.9 & - & 14.2 & 0.65 \\
\hline $\begin{array}{l}\text { Ramírez-Gómez et al. } \\
(2017)^{30}\end{array}$ & $\begin{array}{l}\text { Argentina, } \\
\text { Colombia, } \\
\text { Ecuador }\end{array}$ & 255 & 27.45 & 4.7 & 9.8 & 3.92 & 12.94 & 6.27 & 6.27 & - \\
\hline Isaís-Millán et al. (2016) & Mexico & 63 & 12.6 & - & - & - & - & - & - & - \\
\hline $\begin{array}{l}\text { Rodríguez-Violante et al. } \\
(2014)^{32}\end{array}$ & Mexico & 300 & 10.6 & 1.3 & 3 & 3 & 8.6 & 4.6 & 14.3 & 0 \\
\hline
\end{tabular}

ICD: Impulse control disorder; PD: Parkinson's disease; GD: gambling disorder; HS: hypersexuality; CB: compulsive buying disorder; CE: compulsive binge eating disorder; DDS: dopamine dysregulation syndrome; ${ }^{*}$ Two-year observational period: study visits: baseline, year 1, year $2 ;{ }^{* \star}$ Life time prevalence; ${ }^{\star \star \star}$ Current prevalence. 


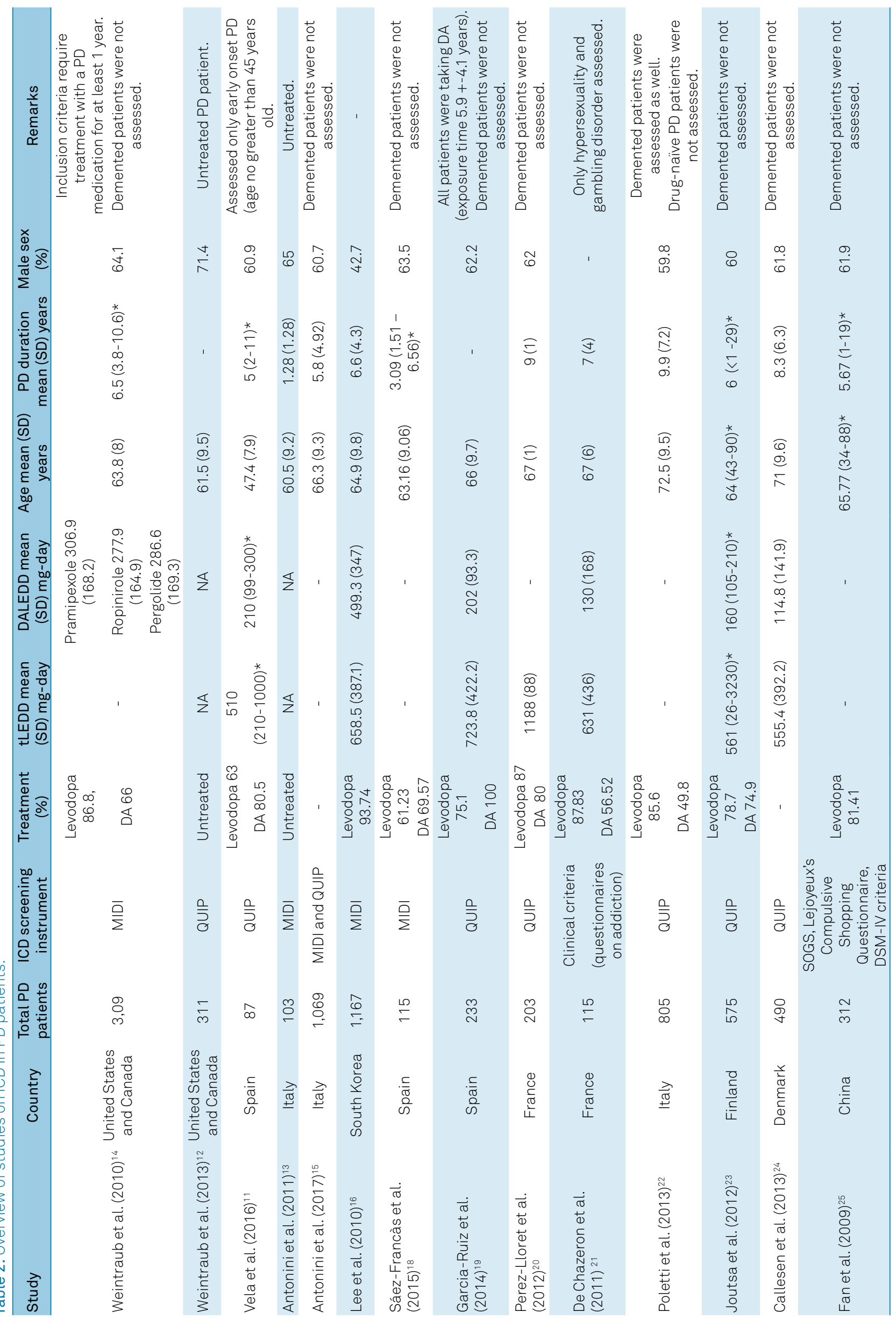




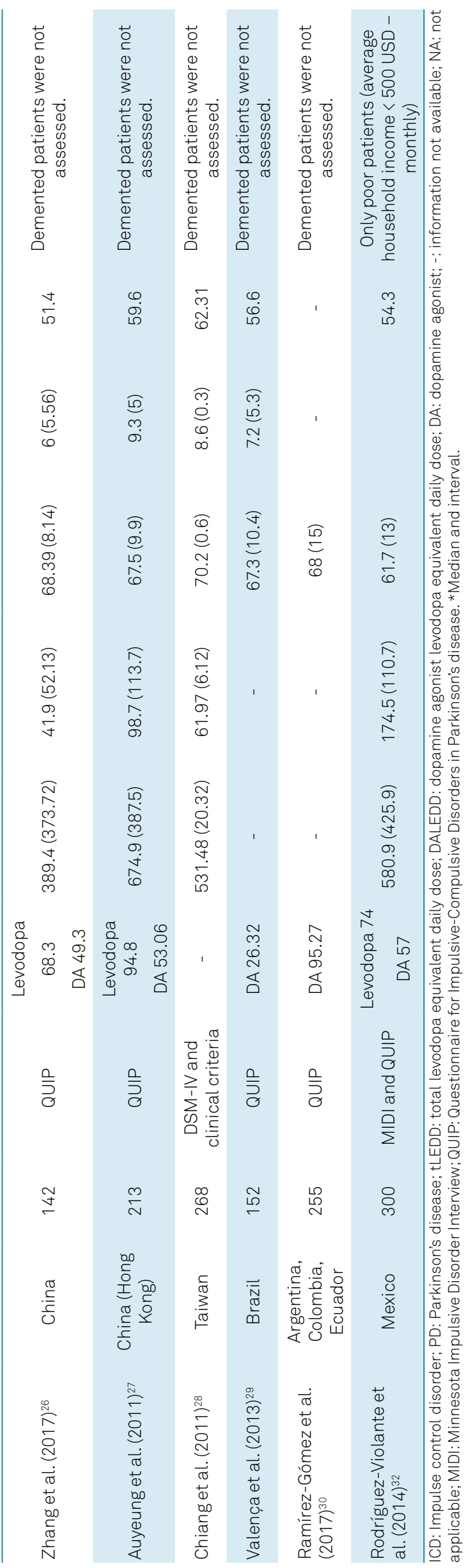

\section{Risk factors}

Factors associated with the development of ICDs among patients with PD include: early onset of motor symptoms, novelty-seeking personality trait, being unmarried, personal or family history of alcohol or recreational drug abuse, smoking, depression, mania, anxiety, obsessive-compulsive symptoms, REM sleep behavior disorder and personal or family history of ICD ${ }^{11,14,15,16,24,29,30,33,34}$. Some studies have reported associations with the use of monoamine oxidase $\mathrm{B}$ inhibitors ${ }^{19}$, catechol-O-methyltransferase inhibitors ${ }^{20,22,33}$ and amantadine ${ }^{14}$. Associations with cognition, intensity of motor symptoms, laterality, fluctuations, tremor or the akinetic rigid syndrome were not identified, suggesting that these specific characteristics of PD do not contribute to the development of ICDs ${ }^{20,33}$.

Impulse control disorders are more common among patients treated with $\mathrm{DAs}^{16,17,19}$. Many studies suggest that ICDs are associated with the use of high doses of these agents $^{11,14,16}$. As a rule, symptoms appear after the onset of medication or soon after dose adjustments ${ }^{35}$. A mean latency of 23 months after the onset of dopaminergic medication has been described ${ }^{36}$. The ICD may occur in the presence of stable doses or a long time after the onset of treatment. Prolonged treatment of six or more years was described as an independent risk factor for the appearance of ICDs among patients with PD in one study ${ }^{37}$ but not in others ${ }^{19}$.

The frequency of ICDs tends to be increased among patients subjected to DA monotherapy compared with levodopa $\mathrm{a}^{20}$. The use of a DA as an adjuvant therapy seems to further increase the odds for developing an ICD ${ }^{16,44}$. In earlyonset PD patients, treatment with DAs increased the risk for ICDs seven-fold ${ }^{11}$.

The association of ICDs and the use of DAs exhibits more of a class effect ${ }^{14}$. The ICDs were associated with use of pramipexole, pergolide, ropinirole, bromocriptine, apomorphine, rotigotine and piribedil $1^{14,16,19,24,25,26,27,30,35}$. The frequency of ICDs was similar for pramipexole and ropinirole in the DOMINION study ( $17.7 \%$ versus $15.5 \%)^{14}$. No difference in ICD development was noted between patients treated with immediate- or extended-release oral DAs ${ }^{19,31}$.

Recent studies suggest that the increased rate of ICDs among patients treated with oral versus transdermal DAs is associated with the medication formulation and route of administration ${ }^{15,19,38}$. Consistently increased plasmwa levels and delivery through a route that avoids erratic gastric emptying and other abnormalities of gastrointestinal motility associated with PD may account for the relatively low risk of ICDs found with transdermal rotigotine delivery.

An association of ICDs with the use of levodopa was not found ${ }^{16}$; however, a relationship with high doses of this drug has been described ${ }^{14}$. Concomitant use of levodopa increases the odds of developing ICDs by $50 \%$ among patients who use DAs ${ }^{14}$.

Efforts to identify the contribution of each factor for a specific ICD in PD showed that drug-induced mania, the use of DAs, early-onset of motor symptoms, severe depression and 
anxiety are risk factors for the development of gambling disorder $^{33}$. Male sex, psychotic symptoms, dyskinesias and early onset of motor symptoms are associated with hypersexuality $^{11,17,36,39}$. Female sex and obesity are correlated with binge eating ${ }^{11,14}$. Obesity, female sex and dyskinesia showed a relationship with compulsive buying ${ }^{10}$. Multiple ICDs tend to occur more frequently among younger PD patients and patients with intense dyskinesia or with previous or current alcoholism ${ }^{33}$.

\section{Neuropsychological aspects}

Patients with PD and ICD tend to be described as shy with poor social skills, low self-esteem, beliefs based on a more negative perception of the disease, dysfunctional coping and paranoid ideation ${ }^{39}$.

Some studies reported poorer performance in tasks that assess the executive functions of the frontal lobes ${ }^{40}$. The most common abnormalities are seen in the go/no-go task and the Trail Making test, which assess the cortical areas more vulnerable to the influence of dopamine levels, such as the ventromedial and orbitofrontal cortices, and more susceptible to the effects of dopaminergic medications ${ }^{40,41}$. However, other studies have found that patients with ICDs perform better in tasks related to attention, verbal and semantic fluency ${ }^{41}$.

A common characteristic of the cognitive dysfunctions associated with ICDs among patients with PD is that they involve abnormalities related to cognitive flexibility, reversal learning and reinforcement, all of which are related to the frontal cortex and ventral striatum ${ }^{42}$. Patients with PD and ICDs exhibit a preference for more immediate rewards and a tendency to undervalue delayed rewards ${ }^{42}$. One study found that behavioral inhibition was almost absent among patients with ICD, with reductions in negative and increases in positive feedback learning ${ }^{43}$. Small rewards induced risk-taking behaviors. Stimulation by means of dopamine replacement therapy may counterbalance the normal effects of negative errors of prediction. The response persists despite punishment. Patients with PD and ICD seem unable to correctly predict the usefulness of inhibitory responses, especially when correct inhibition of a stimulus is not rewarded.

\section{Genetics and epigenetics}

The presence of ICDs in some patients with PD who use small doses of dopaminergic drugs suggests that a genetic predisposition may play a relevant role in the development of this condition ${ }^{10}$. Impulse control disorders have been reported in some types of hereditary PD (PINK1 and parkin) in which symptoms tend to be more intense and appear ear$\operatorname{lier}^{44}$. Although the frequency of patients with at least one ICD is comparable between parkin-PD and nonmutated PD, a higher frequency of compulsive buying and binge eating is found in the parkin-PD group ${ }^{44}$.

Gene polymorphisms are involved in the susceptibility to ICDs ${ }^{10}$. Polymorphisms related to the dopamine and serotonin metabolism may predict the effect of levodopa in ICDs, including variants related to dopamine receptors DRD1, DRD2, DRD3 and DRD4; the kappa opioid receptor; HTR2A serotonin receptor; DOPA decarboxylase; NMDA-GRIN2B receptor and catechol-O-methyltransferase ${ }^{10,45}$. These polymorphisms are also associated with substance dependence disorders and ICDs in the overall population ${ }^{5,10}$.

In a study of 276 patients with PD, the hereditability of ICDs was estimated to be $57 \%{ }^{45}$. This finding is comparable to previous estimations on hereditability for substance addiction and gambling disorder in the general population ${ }^{5,10,45}$. Genotypes from 13 candidate variants allowed improved predictability of ICDs compared with predictions based on clinical endpoints ${ }^{45}$. The combination of a genetic panel (OPRK1, HTR2A, and DDC) and clinical variables (age, gender, duration of follow-up, dopamine replacement therapy) further increased the accuracy of the model ${ }^{45}$.

Epigenetic mechanisms common to dyskinesia and ICDs have been suggested, such as the accumulation of transcription regulation factor delta-FosB ${ }^{10}$. The resulting dysfunction is associated with structural changes in synapses and neuronal spines, leading to abnormal plasticity. Pramipexole activates delta-FosB expression in the ventral striatum even after lesions in the dopaminergic system. Natural gratifications, such as those afforded by food or sex, increase delta-FosB expression in the nucleus accumbens, striatum, prefrontal cortex and ventral tegmental area. Elevated delta-FosB expression following chronic use of dopaminergic medication may contribute to the development of ICDs by increasing individual reward-driven motivation ${ }^{10}$.

\section{Pathophysiology}

An ICD likely arises from complex interactions between the medications used and predisposing pharmacological and nonpharmacological factors ${ }^{10}$. An underlying hyperdopaminergic state was suggested as the cause of ICDs among patients with PD (Figure). The anatomical substrate seems to be similar to the one for chemical dependency, which is related to abnormalities in the reward system involving the ventral striatal dopaminergic pathways ${ }^{10}$. Increased release of endogenous dopamine and potentially reduced density of D2/ D3 receptors are characteristics of ICDs among patients with PD. Dopaminergic treatment may cause hyperstimulation of a relatively preserved ventral striatum, resulting in a lack of control of the reward perception system. In addition, through its connections with the nucleus accumbens, the amygdala and a hyperactive ventromedial subthalamic nucleus may induce symptoms of ICD among patients with PD ${ }^{35}$.

Repeated administration of levodopa to patients with PD increases the firing rate of dopaminergic neurons. Although levodopa increases the activity of dopaminergic neurons, dopamine release also limits the system's ability to respond to new pharmacological stimuli ${ }^{10}$. Repeated administration of DAs followed by a period of abstinence increases the proportion of firing neurons in the ventral tegmental area via 
A

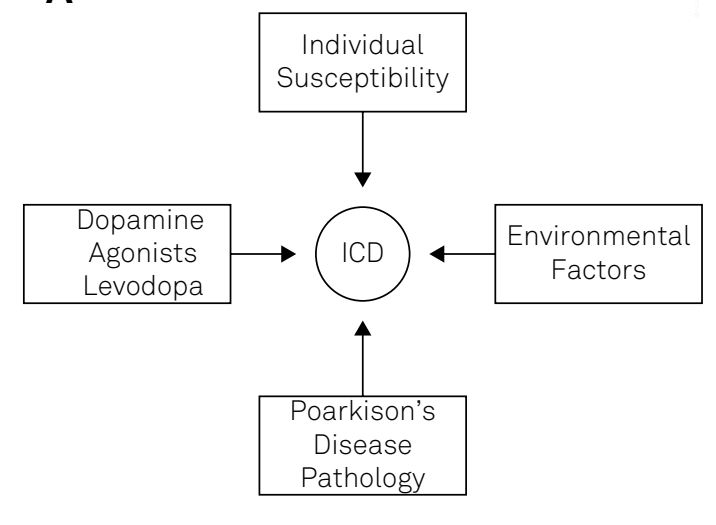

B

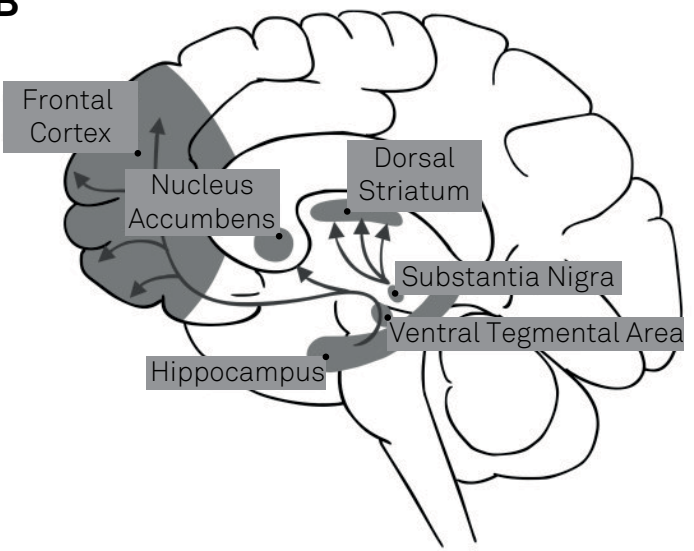

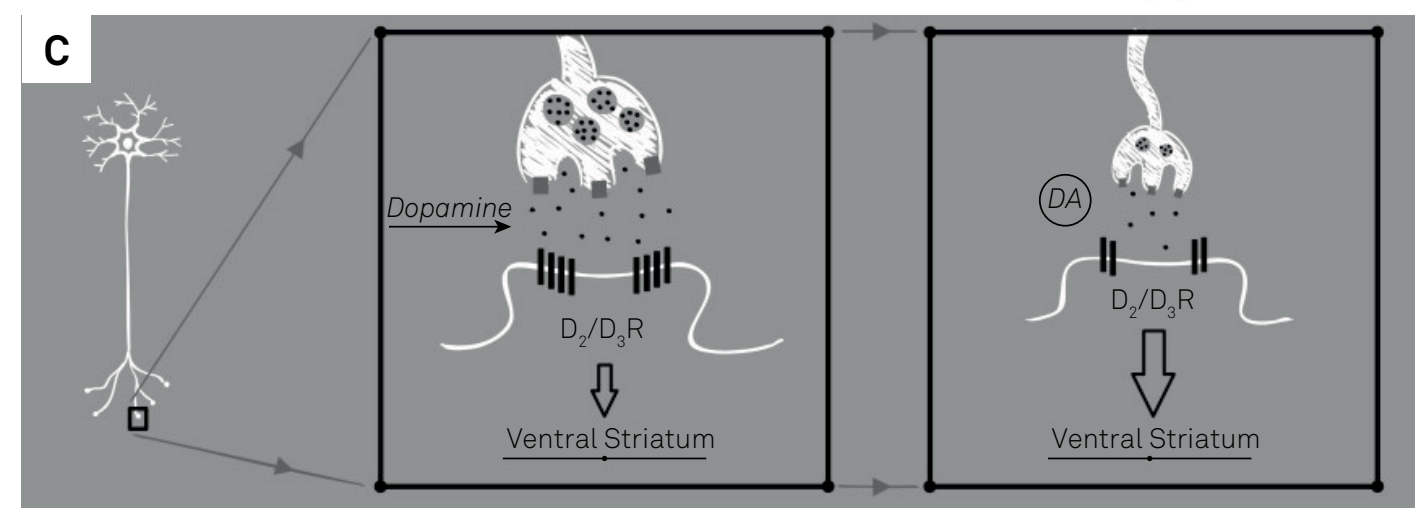

Figure. Hypothetical pathophysiology of impulse control disorder (ICD) in Parkinson's disease (PD). A) The ICD most likely arises from complex interactions between dopaminergic drugs, predisposing individual susceptibility and environmental factors. B) Mesocorticolimbic pathways. Dopamine projections towards the ventral striatum are relatively spared compared with projections towards the dorsal striatum. Dopaminergic medication overstimulates postsynaptic D2/D3 receptors that are abundant in the ventral striatum, increasing activity in the corresponding reward-related brain areas, and reducing the interaction with the prefrontal cortex, thereby decreasing the processing of reward value and hindering reinforcement for perceptions of negative effects. Continuous stimulation of the hippocampus makes individuals persevere in impulsive behaviors. C) Dopamine denervation, and potentially reduced density of D2/D3 receptors, induce increased receptor sensitivity for endogenous and exogenous dopamine.

a method analogous to the effect of repeated administration of levodopa on the substantia nigra. The system thus begins to exhibit an excessive response to stimuli, resulting in an increased firing rate of dopaminergic neurons (overdose hypothesis) ${ }^{10}$.

The preferential abnormal activation of D2 and D3 dopamine receptors by DAs increases the activity of the ventral striatum during reward anticipation but reduces the interaction with the prefrontal cortex, thereby decreasing the processing of the reward value and hindering reinforcement of perceptions of negative effects ${ }^{10,35}$. Continuous stimulation of the hippocampus makes individuals persevere in impulsive behaviors.

Joint stimulation of serotonergic receptors by DAs may affect the impulse control system ${ }^{10,35}$. Low serotonin levels increase the neuronal activity associated with negative outcomes in the dorsolateral cortex, whereas high levels decrease such activity. Dopaminergic and serotonergic dysfunctions, related to a multipolymorphism profile comprised of genes implicated in monoaminergic, glutamatergic and opioid signaling pathways, may explain the inability of patients with ICD to wait for gratification, thus contributing to dysfunctional behaviors ${ }^{10,35,45}$.

\section{Treatment}

Patients and their relatives should be informed about the possibility of ICDs when levodopa or DAs are prescribed ${ }^{46}$. Clinicians should proactively investigate symptoms of impulsivity at each medical visit. For patients with a history of alcoholism, substance dependence or previous ICD, levodopa monotherapy may represent the most appropriate initial treatment regardless of the patient's age. Behavioral changes, such as an increasing tendency towards insomnia, not eating meals at the usual time, forgetting to take medication and missing days at work, should serve as warnings for ICDs ${ }^{46}$.

Treatment should be individualized based on the intensity of symptoms, the patient's neuropsychiatric profile, social support and motor symptoms ${ }^{46}$. Even after attaining remission, patients should be closely monitored because relapse may occur ${ }^{20}$. However, many patients rate their 
behavior as nondeleterious. In addition, the degree of distress in patients and their relatives should be taken into account. Divergence of opinions among patients, their relatives and caregivers may represent a determinant for a more ethical therapeutic option ${ }^{17,46}$.

There is a remarkable paucity of high-quality evidence available to guide the management of ICDs in $\mathrm{PD}^{46}$. Indeed, there are few controlled clinical trials and the evidence is largely based on small-sized, low-quality studies. Recognizing the dominant role of the DA in inducing or triggering ICDs, management of the DA by dose reduction, discontinuation or replacement is the first therapeutic imperative ${ }^{46}$. Dose reduction should be based on the severity of symptoms, patient's response and tolerability. When symptoms are sufficiently intense, the dose of the DA should be immediately reduced. If the patient does not rapidly improve over the following two weeks, the medication should be discontinued ${ }^{17,46}$. Reduction of the levodopa dose may be necessary.

However, patients with an ICD are often reluctant to decrease or discontinue the medication due to the reappearance of motor symptoms and occurrence of abstinence syndrome ${ }^{46}$. One study found that $19 \%$ of patients with an ICD developed abstinence syndrome following discontinuation of their $\mathrm{DA}^{47}$.

Deep-brain stimulation of subthalamic nuclei (STN-DBS) for treatment of ICDs is debatable ${ }^{48}$. The STN-DBS induces impulsive behaviors in some patients. However, discontinuation or reduction of the dose of DAs after STN-DBS resulted in remission of ICDs ${ }^{48}$. The appearance of impulsive disorders after surgery is correlated with younger age and borderline, schizoid or schizotypal personality traits. Hypersexuality and gambling disorder respond better to STN-DBS in contrast to compulsive buying and multiple ICDs ${ }^{48}$.

According to some suggestions, topiramate, zonisamide and opioid antagonists (nalmefene, naltrexone) may be effective for the treatment of gambling disorder among patients with $\mathrm{PD}^{17}$. The use of antipsychotics for patients with PD and ICD is controversial ${ }^{17,46}$. Quetiapine and clozapine are effective for the treatment of patients who need antipsychotics, with the advantage of not causing deleterious effects on the motor function. Some case reports suggest that clozapine may be used for hypersexuality ${ }^{46}$.

Although described as a risk factor for ICDs among patients with $\mathrm{PD}^{14,49}$, one study suggested that amantadine may be used for the treatment of gambling disorder ${ }^{50}$.

Cognitive behavioral therapy may be indicated for the treatment of ICD symptoms among patients with $\mathrm{PD}^{51}$. The focus of intervention is on adjustment issues related to the acceptance of this chronic disease. Additional participation in support groups may provide patients an opportunity to discuss and explore the personal history behind their behaviors and attenuate psychological and emotional problems. Ethical and religious support may be helpful. When discontinuation of DAs fails to provide relief for ICDs, patients and their relatives may find support in fellowships, such as "Gamblers Anonymous" ${ }^{17,51}$. Useful advice by clinical practitioners to patients and their relatives includes practices to avoid exposure to the temptation to gamble, such as installation of firewalls against Internet gambling pop-ups. Rigorous control of financial management by relatives is mandatory in many cases.

\section{Prognosis}

A few studies have analyzed the factors related to the prognosis of ICDs in patients with $\mathrm{PD}^{41,52}$. In one prospective cohort study, $40 \%$ of patients had prolonged remission ${ }^{41}$. This outcome was associated with better working memory and increased use of atypical antipsychotics and antidepressants. Gambling disorders had a better prognosis compared with other types of ICDs. High doses of DAs and male sex were associated with ICD persistance ${ }^{52,53}$.

\section{PUNDING}

Punding is a stereotyped motor behavior characterized by a strong fascination for excessively and repetitively collecting, organizing, disorganizing, examining and handling objects ${ }^{54}$. These behaviors are irresistible and may be simple or involve more complex actions associated with specific activities or hobbies, as in hobbyism ${ }^{54}$. Hoarding and walkabouts may be considered behavioral variants within the punding spectrum. Patients report their motivation to perform the stereotyped actions involves fascination and curiosity, even though the targeted activity may be purposeless. These behaviors are similar to the behaviors that occur in obsessive-compulsive disorder, although they are ego-syntonic, more idiosyncratic and less stressful ${ }^{54}$. Any interruption or interference makes the patient irritated, anxious and frustrated. Patients are aware of the inadequate nature of their actions but are unable to stop them. These behaviors interfere with medication intake, eating and sleeping, leading to social withdrawal and disintegration of family relationships. Sleep disorders, ICD and dopamine dysregulation syndrome (DDS) are commonly associated with punding. A correlation exists between the punding severity and dyskinesia ${ }^{54}$.

Diagnosis may be difficult because patients typically do not perceive their behaviors as problematic ${ }^{54,55}$. The prevalence of punding varies among different studies due to disparities in the assessed population, dose of dopaminergic medication, study methods and diagnostic criteria. Punding is estimated to affect $0.34 \%$ to $14 \%$ of patients with $\mathrm{PD}^{54}$. The prevalence of punding and related behaviors, such as hobbyism and walkabout, seems to be stable over time ${ }^{15}$.

Factors associated with punding and hobbyism include impulsivity, low disease-related quality of life, younger age at onset of PD, male sex, insomnia, smoking, substance abuse, anxiety, psychotic symptoms, collectionism, lascivious 
behavior and dyskinesia ${ }^{16,39}$. Punding and related behaviors are more severe among patients with juvenile PD due to mutation in the parkin gene $e^{44}$.

Numerous studies have reported a relationship between punding and a high dose and long duration of treatment with levodopa and $\mathrm{DAs}^{36,54,55}$. A lack of dopaminergic terminals and intermittent levodopa administration results in abnormal dopamine release and hyperactivity of the ventral and dorsal striatal circuits, especially in D1 receptors ${ }^{10,54,56}$. The imbalance represented by increased connectivity in the striatum and reduced connectivity with the prefrontal cortical regions involved in the control of executive functions and directed attention may explain the purposeless repetitive behavior that occurs in punding ${ }^{55,56}$.

There is insufficient evidence for the efficacy of any treatment for the treatment of punding in DP. Symptoms may improve following reduction of the dose or discontinuation of levodopa or DAs ${ }^{55}$. Caution is required to achieve a careful balance between punding control and worsening of motor symptoms. Atypical antipsychotics, such as quetiapine and clozapine, may potentially improve symptoms. Repetitive, low frequency transcranial magnetic stimulation with inhibition of the dorsolateral prefrontal cortex transiently reduced punding behavior in a manner similar to that for patients with levodopa-induced diskinesia ${ }^{57}$.

\section{DOPAMINE DYSREGULATION SYNDROME}

Dopamine dysregulation syndrome involves the abuse of dopaminergic drugs, particularly levodopa and apomorphine $^{58,59}$. The syndrome meets the diagnostic criteria for substance dependence: compulsive and persistent use of medication in doses above the therapeutic needs, intoxication symptoms similar to those induced by cocaine and methamphetamine, and abstinence syndrome following reduction or discontinuation of the medication. Patients report a strong need to use levodopa, which gives a feeling of pleasure. Therefore, the medications are used to avoid the symptoms related to the ill feeling that appears in the off period. Patients exhibit intense and disabling, albeit well-tolerated dyskinesia, mania, euphoria, irritability, psychomotor agitation, excitability, low tolerance to frustration, auditory hallucinations and paranoia ${ }^{58}$. Abrupt mood changes, dysphoria, depression, anxiety and irritability are common occurrences on each attempt to reduce the dose of the dopaminergic medication ${ }^{58,59}$. The prevalence of DDS varies from $0.6 \%$ to $7.7 \%{ }^{59}$. No difference according to sex is noted.

Risk factors include: younger age at onset of PD symptoms, use of large amounts of dopaminergic drugs, long duration of antiparkinson treatment, previous history of alcoholism or drug abuse, previous history of mood disorders, family history of PD and impulsive personality ${ }^{58,59}$. Repeated wearing off experiences at the end of the levodopa effect and coexistence of chronic depression increase the feeling of gratification afforded by levodopa to the point that the search for dopaminergic drugs becomes compulsive.

The pathophysiology of DDS is associated with sensitization of dopaminergic transmission in the ventral striatum, resulting in the feeling of craving. Functional imaging tests have shown evidence of a large dopamine release in the ventral striatum following dopamine administration among patients with DDS $^{58,59}$

Most evidence reported on the management of ICDs comes from empirical data with limited clinical trials to identify effective treatment. The management of DDS is often unsatisfactory ${ }^{58}$. Reduction of medication typically improves DDS, but relapse is frequent. Therapeutic optimization requires active monitoring by the patient's relatives and doctors. Reduction of the levodopa dose has been associated with resolution of DDS in less than $10 \%$ of patients ${ }^{58}$. Disabling dyskinesia and off period dysphoria with distress symptoms may respond to continuous dopaminergic stimulation by means of subcutaneous apomorphine infusion. Low dose clozapine and quetiapine over short periods of time may help in selected cases, especially when accompanied by psychosis or mania ${ }^{58}$. Antidepressants, lithium and psychotherapy are typically ineffective. Intestinal levodopa infusion and STN-DBS may improve DDS symptoms in some patients ${ }^{48,60}$. Prolonged remission has been associated with the use of clozapine, duodenal levodopa infusion and STN-DBS, and less associated with apomorphine administered through an infusion pump ${ }^{58}$.

\section{References}

1. Evenden JL. Varieties of impulsivity. Psychopharmacology (Berl). 1999 Oct;146(4):348-61. https://doi.org/10.1007/PL00005481

2. Schreiber L, Odlaug BL, Grant JE. Impulse control disorders: updated review of clinical characteristics and pharmacological management. Front Psychiatry. 2011;2:1. https://doi.org/10.3389/fpsyt.2011.00001

3. Baik JH. Dopamine signaling in reward-related behaviors. Front Neural Circuits. 2013 Oct;7:152. https://doi.org/10.3389/fncir.2013.00152
4. Müller A, Rein K, Kollei I, Jacobi A, Rotter A, Schütz P et al. Impulse control disorders in psychiatric inpatients. Psychiatry Res. 2011 Aug;188(3):434-8. https://doi.org/10.1016/j.psychres.2011.04.006

5. Nautiyal KM, Okuda M, Hen R, Blanco C. Gambling disorder: an integrative review of animal and human studies. Ann N Y Acad Sci. 2017 Apr;1394(1):106-27. https://doi.org/10.1111/nyas.13356

6. Tamam L, Bican M, Keskin N. Impulse control disorders in elderly patients. Compr Psychiatry. 2014 May;55(4):1022-8. https://doi.org/10.1016/j.comppsych.2013.12.003 
7. Bancos I, Nannenga MR, Bostwick JM, Silber MH, Erickson D, Nippoldt TB. Impulse control disorders in patients with dopamine agonist-treated prolactinomas and nonfunctioning pituitary adenomas: a case-control study. Clin Endocrinol (Oxf). 2014 Jun;80(6):863-8. https://doi.org/10.1111/cen.12375

8. Cornelius JR, Tippmann-Peikert M, Slocumb NL, Frerichs CF, Silber MH. Impulse control disorders with the use of dopaminergic agents in restless legs syndrome: a case-control study. Sleep. 2010 Jan;33(1):81-7.

9. Weintraub D, Claassen DO. Impulse control and related disorders in Parkinson's disease. Int Rev Neurobiol. 2017;133:679-717. https://doi.org/10.1016/bs.irn.2017.04.006

10. Voon V, Napier TC, Frank MJ, Sgambato-Faure V, Grace AA, Rodriguez-Oroz M et al. Impulse control disorders and levodopa-induced dyskinesias in Parkinson's disease: an update. Lancet Neurol. 2017 Mar;16(3):238-50. https://doi.org/10.1016/S1474-4422(17)30004-2

11. Vela L, Martínez Castrillo JC, García Ruiz P, Gasca-Salas C, Macías Macías Y, Pérez Fernández E et al. The high prevalence of impulse control behaviors in patients with early-onset Parkinson's disease: A cross-sectional multicenter study. J Neurol Sci. 2016 Sep;368:150-4. https://doi.org/10.1016/j.jns.2016.07.003

12. Weintraub D, Papay K, Siderowf A; Parkinson's Progression Markers Initiative. Screening for impulse control symptoms in patients with de novo Parkinson disease: a case-control study. Neurology. 2013 Jan;80(2):176-80. https://doi.org/10.1212/WNL.0b013e31827b915c

13. Antonini A, Siri C, Santangelo G, Cilia R, Poletti M, Canesi $M$ et al. Impulsivity and compulsivity in drug-naïve patients with Parkinson's disease. Mov Disord. 2011 Feb;26(3):464-8. https://doi.org/10.1002/mds.23501

14. Weintraub D, Koester J, Potenza MN, Siderowf AD, Stacy M, Voon V et al. Impulse control disorders in Parkinson disease: a cross-sectional study of 3090 patients. Arch Neurol. 2010 May;67(5):589-95. https://doi.org/10.1001/archneurol.2010.65

15. Antonini A, Barone P, Bonuccelli U, Annoni K, Asgharnejad M, Stanzione P. ICARUS study: prevalence and clinical features of impulse control disorders in Parkinson's disease. J Neurol Neurosurg Psychiatry. 2017 Apr;88(4):317-24. https://doi.org/10.1136/jnnp-2016-315277

16. Lee JY, Kim JM, Kim JW, Cho J, Lee WY, Kim HJ et al. Association between the dose of dopaminergic medication and the behavioral disturbances in Parkinson disease. Parkinsonism Relat Disord. 2010 Mar;16(3):202-7. https://doi.org/10.1016/j.parkreldis.2009.12.002

17. Raja M, Bentivoglio AR. Impulsive and compulsive behaviors during dopamine replacement treatment in Parkinson's Disease and other disorders. Curr Drug Saf. 2012 Feb;7(1):63-75. https://doi.org/10.2174/157488612800492726

18. Sáez-Francàs N, Martí Andrés G, Ramírez N, Fàbreugues 0 Álvarez-Sabin J, Casas M et al. [Clinical and psychopathological factors associated with impulse control disorders in Parkinson's disease]. Neurología. 2016;31(4):231-8. Spanish. https://doi.org/10.1016/j.nrl.2015.05.002

19. Garcia-Ruiz PJ, Martinez Castrillo JC, Alonso-Canovas A, Herranz Barcenas A, Vela L, Sanchez Alonso P et al. Impulse control disorder in patients with Parkinson's disease under dopamine agonist therapy: a multicentre study. J Neurol Neurosurg Psychiatry. 2014 Aug;85(8):840-4. https://doi.org/10.1136/jnnp-2013-306787

20. Perez-Lloret S, Rey MV, Fabre N, Ory F, Spampinato U, Brefel-Courbon $\mathrm{C}$ et al. Prevalence and pharmacological factors associated with impulse-control disorder symptoms in patients with Parkinson disease. Clin Neuropharmacol. 2012 Nov-Dec;35(6):261-5. https://doi.org/10.1097/WNF.0b013e31826e6e6d

21. de Chazeron I, Llorca PM, Chéreau-Boudet I, Blanc O, Perriot J, Ouchchane L et al. Hypersexuality and pathological gambling in Parkinson's disease: A cross-sectional case-control study. Mov Disord. 2011 Sep;26(11):2127-30. https://doi.org/10.1002/mds.23845
22. Poletti M, Logi C, Lucetti C, Del Dotto P, Baldacci F, Vergallo A et al. A single-center, cross-sectional prevalence study of impulse control disorders in Parkinson disease: association with dopaminergic drugs. J Clin Psychopharmacol. 2013 Oct;33(5):691-4. https://doi.org/10.1097/JCP.0b013e3182979830

23. Joutsa J, Martikainen K, Vahlberg T, Voon V, Kaasinen V. Impulse control disorders and depression in Finnish patients with Parkinson's disease. Parkinsonism Relat Disord. 2012 Feb;18(2):15560. https://doi.org/10.1016/j.parkreldis.2011.09.007

24. Callesen MB, Weintraub D, Damholdt MF, Møller A. Impulsive and compulsive behaviors among Danish patients with Parkinson's disease: prevalence, depression, and personality. Parkinsonism Relat Disord. 2014 Jan;20(1):22-6. https://doi.org/10.1016/j.parkreldis.2013.09.006

25. Fan W, Ding H, Ma J, Chan P. Impulse control disorders in Parkinson's disease in a Chinese population. Neurosci Lett. 2009 Nov;465(1):6-9. https://doi.org/10.1016/j.neulet.2009.06.074

26. Zhang Y, He AQ, Li L, Chen W, Liu ZG. Clinical characteristics of impulse control and related disorders in Chinese Parkinson's disease patients. BMC Neurol. 2017 May;17(1):98. https://doi.org/10.1186/s12883-017-0874-6

27. Auyeung M, Tsoi TH, Tang WK, Cheung CM, Lee CN, Li R et al. Impulse control disorders in Chinese Parkinson's disease patients: the effect of ergot derived dopamine agonist. Parkinsonism Relat Disord. 2011 Sep;17(8):635-7. https://doi.org/10.1016/j.parkreldis.2011.06.001

28. Chiang HL, Huang YS, Chen ST, Wu YR. Are there ethnic differences in impulsive/compulsive behaviors in Parkinson's disease? Eur J Neurol. 2012 Mar;19(3):494-500. https://doi.org/10.1111/j.1468-1331.2011.03571.x

29. Valença GT, Glass PG, Negreiros NN, et al. Past smoking and current dopamine agonist use show an independent and dosedependent association with impulse control disorders in Parkinson's disease. Parkinsionism Relat Disord. 2013;19(7):698-700. Https://doi.org/10.1016/j.parkreldis.2013.03.004

30. Ramírez Gómez CC, Serrano Dueñas M, Bernal O, Araoz N, Sáenz Farret M, Aldinio V et al. A Multicenter comparative study of impulse control disorder in Latin American patients with Parkinson Disease. Clin Neuropharmacol. 2017 Mar/Apr;40(2):51-55. https://doi.org/10.1097/WNF.0000000000000202

31. Isaias-Millan S, Pina-Fuentes D, Guzman-Astorga C, CervantesArriaga A, Rodriguez-Violante M. Prevalencia de trastornos neuropsiquiatricos en pacientes con enfermedad de Parkinson (EP) no tratados. Gac Med Mex. 2016;152:357-63.

32. Rodríguez-Violante M, González-Latapi P, Cervantes-Arriaga A, Camacho-Ordoñez A, Weintraub D. Impulse control and related disorders in Mexican Parkinson's disease patients. Parkinsionism Relat Disord. 2014;20(8):907-10. https://doi.org/10.1016/j.parkreldis.2014.05.014

33. Voon V, Sohr M, Lang AE, Potenza MN, Siderowf AD, Whetteckey $\mathrm{J}$ et al. Impulse control disorders in Parkinson disease: a multicenter case: control study. Ann Neurol. 2011 Jun;69(6):986-96. https://doi.org/10.1002/ana.22356

34. Fantini ML, Figorilli M, Arnulf I, Zibetti M, Pereira B, Beudin Pet al. Sleep and REM behaviour disorder in Parkinson's disease with impulse controle disorder. J Neurol Neurosurg Psychiatry. 2018;89:305-10. https://doi.org/10.1136/jnnp-2017-316576

35. Callesen MB, Scheel-Krüger J, Kringelbach ML, Møller A. A systematic review of impulse control disorders in Parkinson's disease. J Parkinsons Dis. 2013;3(2):105-38. https://doi.org/10.3233/JPD-120165

36. Gallagher DA, O'Sullivan SS, Evans AH, Lees AJ, Schrag A. Pathological gambling in Parkinson's disease: risk factors and differences from dopamine dysregulation: an analysis of published case series. Mov Disord. 2007 Sep;22(12):1757-63. https://doi.org/10.1002/mds.21611 
37. Giladi N, Weitzman N, Schreiber S, Shabtai H, Peretz C. New onset heightened interest or drive for gambling, shopping, eating or sexual activity in patients with Parkinson's disease: the role of dopamine agonist treatment and age at motor symptoms onset. J Psychopharmacol. 2007 Jul;21(5):501-6. https://doi.org/10.1177/0269881106073109

38. Antonini A, Chaudhuri KR, Boroojerdi B, Asgharnejad M, Bauer L, Grieger F et al. Impulse control disorder related behaviours during long-term rotigotine treatment: a post hoc analysis. Eur J Neurol. 2016 Oct;23(10):1556-65. https://doi.org/10.1111/ene.13078

39. Garlovsky JK, Simpson J, Grünewald RA, Overton PG. Impulse control disorders in Parkinson's disease: predominant role of psychological determinants. Psychol Health. 2016 Dec;31(12):1391-414. https://doi.org/10.1080/08870446.2016.1218879

40. Bentivoglio AR, Baldonero E, Ricciardi L, De Nigris F, Daniele A. Neuropsychological features of patients with Parkinson's disease and impulse control disorders. Neurol Sci. 2013 Jul;34(7):1207-13. https://doi.org/10.1007/s10072-012-1224-5

41. Siri C, Cilia R, Reali E, Pozzi B, Cereda E, Colombo A et al. Longterm cognitive follow-up of Parkinson's disease patients with impulse control disorders. Mov Disord. 2015 Apr;30(5):696-704. https://doi.org/10.1002/mds.26160

42. Joutsa J, Voon V, Johansson J, Niemelä S, Bergman J, Kaasinen V. Dopaminergic function and intertemporal choice. Transl Psychiatry. 2015 Jan;5(1):e491. https://doi.org/10.1038/tp.2015.12

43. Leplow B, Sepke M, Schönfeld R, Pohl J, Oelsner H, Latzko L et al. Impaired learning of punishments in Parkinson's disease with and without impulse control disorder. J Neural Transm (Vienna). 2017 Feb;124(2):217-25. https://doi.org/10.1007/s00702-016-1648-9

44. Morgante F, Fasano A, Ginevrino M, Petrucci S, Ricciardi L, Bove Fet al. Impulsive-compulsive behaviors in parkin-associated Parkinson disease. Neurology. 2016 Oct;87(14):1436-41. https://doi.org/10.1212/WNL.0000000000003177

45. Kraemmer J, Smith K, Weintraub D, Guillemot V, Nalls MA, Cormier-Dequaire F et al. Clinical-genetic model predicts incident impulse control disorders in Parkinson's disease. J Neurol Neurosurg Psychiatry. 2016 Oct;87(10):1106-11. https://doi.org/10.1136/jnnp-2015-312848

46. Ramirez-Zamora A, Gee L, Boyd J, Biller J. Treatment of impulse control disorders in Parkinson's disease: practical considerations and future directions. Expert Rev Neurother. 2016;16(4):389-99. https://doi.org/10.1586/14737175.2016.1158103

47. Rabinak CA, Nirenberg MJ. Dopamine agonist withdrawal syndrome in Parkinson disease. Arch Neurol. 2010 Jan;67(1):58-63. https://doi.org/10.1001/archneurol.2009.294

48. Merola A, Romagnolo A, Rizzi L, Rizzone MG, Zibetti M, Lanotte $M$ et al. Impulse control behaviors and subthalamic deep brain stimulation in Parkinson disease. J Neurol. 2017 Jan;264(1):40-8. https://doi.org/10.1007/s00415-016-8314-x
49. Weintraub D, Sohr M, Potenza MN, Siderowf AD, Stacy M, Voon V et al. Amantadine use associated with impulse control disorders in Parkinson disease in cross-sectional study. Ann Neurol. 2010 Dec;68(6):963-8. https://doi.org/10.1002/ana.22164

50. Thomas A, Bonanni L, Gambi F, Di lorio A, Onofrj M. Pathological gambling in Parkinson disease is reduced by amantadine. Ann Neurol. 2010 Sep;68(3):400-4. https://doi.org/10.1002/ana.22029

51. Okai D, Askey-Jones S, Samuel M, O'Sullivan SS, Chaudhuri KR, Martin A et al. Trial of CBT for impulse control behaviors affecting Parkinson patients and their caregivers. Neurology. 2013 Feb;80(9):792-9. https://doi.org/10.1212/WNL.0b013e3182840678

52. Joutsa J, Martikainen K, Vahlberg T, Kaasinen V. Effects of dopamine agonist dose and gender on the prognosis of impulse control disorders in Parkinson's disease. Parkinsonism Relat Disord. 2012 Dec;18(10):1079-83.https://doi.org/10.1016/j.parkreldis.2012.06.005

53. Sohtaoğlu M, Demiray DY, Kenangil G, Ozekmekçi S, Erginöz E. Long term follow-up of Parkinson's disease patients with impulse control disorders. Parkinsonism Relat Disord. 2010 Jun;16(5):334-7. https://doi.org/10.1016/j.parkreldis.2010.02.006

54. Spencer AH, Rickards H, Fasano A, Cavanna AE. The prevalence and clinical characteristics of punding in Parkinson's disease. Mov Disord. 2011 Mar;26(4):578-86. https://doi.org/10.1002/mds.23508

55. Fasano A, Ricciardi L, Pettorruso M, Bentivoglio AR. Management of punding in Parkinson's disease: an openlabel prospective study. J Neurol. 2011 Apr;258(4):656-60. https://doi.org/10.1007/s00415-010-5817-8

56. Markovic V, Agosta F, Canu E, Inuggi A, Petrovic I, Stankovic I et al. Role of habenula and amygdala dysfunction in Parkinson disease patients with punding. Neurology. 2017 Jun;88(23):2207-15. https://doi.org/10.1212/WNL.0000000000004012

57. Nardone R, De Blasi P, Höller Y, Christova M, Tezzon F, Trinka E et al. Repetitive transcranial magnetic stimulation transiently reduces punding in Parkinson's disease: a preliminary study. J Neural Transm (Vienna). 2014;121(3):267-74. https://doi.org/10.1007/s00702-013-1100-3

58. Cilia R, Siri C, Canesi M, Zecchinelli AL, De Gaspari D, Natuzzi F et al. Dopamine dysregulation syndrome in Parkinson's disease: from clinical and neuropsychological characterisation to management and long-term outcome. J Neurol Neurosurg Psychiatry. 2014 Mar;85(3):311-8. https://doi.org/10.1136/jnnp-2012-303988

59. Warren N, O'Gorman C, Lehn A, Siskind D. Dopamine dysregulation syndrome in Parkinson's disease: a systematic review of published cases. J Neurol Neurosurg Psychiatry. 2017 Dec;88(12):1060-4.

60. Catalán MJ, Pablo-Fernández E, Villanueva C, Fernández-Diez S, Lapeña-Montero T, García-Ramos R et al. Levodopa infusion improves impulsivity and dopamine dysregulation syndrome in Parkinson's disease. Mov Disord. 2013;28(14):2007-10. https://doi.org/10.1002/mds.25636 